\title{
Cueva Mayor y la Sima de los Huesos (Sierra de Atapuerca, Burgos) en un manuscrito de la Biblioteca Nacional de Madrid de 1795
}

\section{Cueva Mayor and the Sima de los Huesos (Sierra de Atapuerca, Burgos) in a manuscript of Spain's National Library, Madrid, 1795}

\author{
ISAAC Rilova PÉREZ * \\ Ana Isabel Ortega Martínez **
}

RESUMEN

A finales del siglo XVIII, tras la emancipación de la Geografía de las Ciencias Matemáticas y la elevación de la Cartografía a la categoría de disciplina, comienzan a elaborarse mapas en España trazados con precisión y rigor, aunque todavía condicionados por la complementariedad de las fuentes informativas. Tomás López, geógrafo real, remitió un formulario al arzobispado de Burgos para la elaboración del mapa de la diócesis, que fue contestado por don Manuel Francisco de Paula, vicario de la Cuadrilla de Gamonal, quien señala como singularidad más destacable la Cueva

\section{ABSTRACT}

At the end of the XVIIIth century, after the emancipation of Geography from the Mathematical Sciences and the rise of Cartography to the category of a discipline, maps started to be drawn up in Spain with precision and accuracy, although still conditioned by complementary information sources. Tomás López, the Royal geographer, sent, to the Archbishopric of Burgos, a form for making a diocese map. This request was answered by don Manuel Francisco de Paula, vicar of the "Cuadrilla de Gamonal»", who points out to "Cueva Mayor de la Sierra de Atapuerca» as the most outstanding place in the

* Doctor en Historia (UNED)

** Arqueóloga (Universidad de Burgos) 
Mayor de la Sierra de Atapuerca, a cuya descripción dedica casi la mitad de su exposición, y donde se mezclan al unísono, junto a la admiración y el asombro pertinentes, una gran precisión en la información, aunque todavía aderezada con las más peregrinas fabulaciones y quimeras.

\section{PALABRAS CLAVE}

Edad Moderna, España, Burgos, Sierra de Atapuerca, Cueva Mayor. diocese. Almost one half of his statement was a detail description of it, mixing the relevant admiration and amazement with a great naivety, dressed up with the most bizarre fables and legends.

\section{KEY WORDS}

Modern Age, Spain, Burgos, Sierra de Atapuerca, Cueva Mayor.

\section{INTRODUCCIÓN}

Las reformas que inicia la monarquía borbónica, caracterizadas por la instauración de un nuevo ciclo económico y demográfico de signo alcista y el empeño puesto en la reorganización político-administrativa, repercutirá de forma muy positiva en el país. Para ello, las autoridades van a tratar de obtener un conocimiento preciso de la realidad de la Península y de las distintas regiones, de su marco natural, fisonomía y habitantes, sobre la base del óptimo aprovechamiento de recursos ${ }^{1}$. Tan grande empeño se ve obstaculizado por la falta de producción cartográfica nacional. Era necesario potenciar la cartografía en España especialmente cuando, en el último cuarto del siglo XVIII, la geografía había dejado de formar parte de las disciplinas matemáticas e incluso comenzaban a distinguirse geografía y cartografía para que caminaran juntas, aunque autónomas. Para subsanar las carencias de esta última disciplina, Manuel Salvador Carmona ${ }^{2}$ y Alonso Cruzado $^{3}$ reciben una beca para estudiar en París las técnicas del grabado y Juan de la Cruz Cano ${ }^{4}$ y Tomás López, para aprender cartografía. Nos situamos en los años centrales del siglo XVIII.

Tomás López de Vargas Machuca ${ }^{5}$ tras su regreso a España, después de haber sido nombrado geógrafo del Rey, realizó varios proyectos como los mapas

1 Iglesias Rouco, L. S.: Burgos. La ciudad a través de la cartografía histórica, Instituto Municipal de Cultura, 2002, p. 42.

2 Manuel Salvador Carmona (1734-1820) fue un destacado pintor y grabador formado en Francia. De regreso a España se incorporó a la Real Academia de Bellas Artes de San Fernando en la que ostentó el cargo de director de grabado, consiguiendo en 1783 la plaza de Grabador de Cámara del Rey.

3 Alonso Cruzado ( $(-1791)$ trabajó en el Real Laboratorio del Buen Retiro como «adornista de bronce y otros metales".

4 Juan de la Cruz Cano y Olmedilla (1734-1790) es geógrafo y cartógrafo renombrado autor de mapas de las Antillas y del golfo de Méjico, además de un Atlas de España y otro de América. Su Mapa Geográfico de América Meridional es una de las grandes obras de la cartografía española del siglo XVIII.

5 Tomás López y Vargas Machuca (1730-1802), originario de Toledo, después de realizar estudios de gramática, retórica y dibujo en la Academia de Bellas Artes, inició su carrera como geógrafo y cartógra- 
provinciales de Madrid, Jaén, Granada y Córdoba. De la comarca burgalesa realizó un mapa titulado: Mapa geográfico de una parte de la Provincia de Burgos que comprende los partidos de Burgos, Bureva, Castroxeriz, Candemuño, Villadiego, etc ${ }^{6}$.

\section{EL CUESTIONARIO O INTERROGATORIO DE TOMÁS LÓPEZ, GEÓGRAFO REAL}

La pretensión era la elaboración de un Diccionario Histórico Geográfico de España, que se le había encomendado confeccionar, que serviría, a su vez, de complemento a los mapas de las distintas diócesis, o circunscripciones provinciales, para lo cual, en 1766, dirigió un escrito a las autoridades eclesiásticas solicitando datos relativos a las diócesis y parroquias, cuestionario o interrogatorio, como lo define él, que reaprovechó en 1776 para componer su gran obra. Lamentablemente, el trabajo de López no se publicó, pero generó una enorme documentación preparatoria que se conserva manuscrita en varios legajos de la $\mathrm{Bi}$ blioteca Nacional de Madrid y que sirvió para la confección de un mapa general de España.

\section{INTERROGATORIO}

1. Si es Lugar, Villa ó Ciudad, á qué Vicaría pertenece; si es Realengo, o de Señorío o mixto, y el número de vecinos.

2. Si es cabeza de Vicaría ó Partido, Parroquia, Anexo y de qué Parroquia, y si tiene Convento decir de qué Orden y sexo, como también si dentro de la población ó extramuros hay algún Santuario ó Imagen célebre, declarar su nombre y distancia; asimismo el nombre antiguo y moderno del Pueblo, la advocación de la Parroquial, y el Patrón del Pueblo.

3. ${ }^{\circ}$ Se pondrá quántas leguas dista de la principal o Metrópoli, quánto de la cabeza de Partido, y quántos quartos de legua de los Lugares confinantes, expresando en este último particular los que están al Norte, al Mediodía, Levante o Poniente, respecto del Lugar que responde, y quántas leguas ocupa su jurisdicción.

(Continúa)

fo en Madrid, en 1752, habiendo estudiado en el Colegio Imperial. En ese mismo año fue enviado a París por el Marqués de la Ensenada, a propuesta de los marinos Jorge Juan y Antonio Ulloa «para estudiar geografía y levantar el mapa de España». Junto a él enviaron al también geógrafo Juan de la Cruz Cano y Olmedilla y a los grabadores Manuel Salvador Carmona y Alonso Cruzado. Trabajó en París con el abate La Caille y Juan Bautista Bourguignon d'Anville, que eran los mejores geógrafos del momento. A su regreso a España, en 1760 fue nombrado por Carlos III «geógrafo de Su Majestad», colocándole al frente del Gabinete de Geografía recién creado.

${ }^{6}$ ARChivo Municipal de Burgos: Tomás LóPEZ: Mapa en 4 hojas, grabado, color, $85 \times 81 \mathrm{~cm}$., en hojas de 44,5 $\times 54 \mathrm{~cm}$., Madrid, 1874 . 
4. Dirá si está á orilla de algún río, arroyo o laguna, si á la derecha ó la izquierda de él baxando agua abajo; donde nacen estas aguas, en donde y con quien se juntan, y cómo se llaman. Si tienen puentes de piedra, madera ó barcas, con sus nombres, y por qué Lugares pasan.

5. ${ }^{\circ}$ Expresarán los nombres de las sierras, donde empiezan á subir, donde á baxar, con un juicio razonable del tiempo para pasarlas, ó de su magnitud; declarando los nombres de sus puertos, y en donde se ligan y pierden ó conservan sus nombres estas cordilleras con otras.

6. Qué bosques, montes y florestas tiene el Lugar; de qué matas poblado, cómo se llaman, á qué ayre caen y quánto se estiende.

7. Q Quándo y por quién se fundó el Lugar; qué armas tiene y con qué motivo, los sucesos notables de su historia, hombres ilustres que ha tenido, y los edificios ó castillos memorables que aún conserva.

8. ${ }^{\circ}$ Quáles son los frutos más singulares de su terreno, los que carece; quál es la cantidad á que ascienden cada año.

9. Manufacturas y Fábricas que tiene, de qué especies, y por quién establecidas; qué cantidades elaboran cada año; qué artífices sobresalientes en ellas; qué inventos, instrumentos ó máquinas ha encontrado la industria para facilitar los trabajos.

10. Quáles son las Ferias ó Mercados, y los días en que se celebran; qué géneros se comercian, extraen ó reciben en cambio, de dónde y para donde, sus pesos y medidas, compañías y casas de cambio.

$11 .^{\circ}$ Si tiene estudios generales, ó particulares, sus fundaciones, método y tiempo en que se abren; que facultades enseñan, y quáles con más adelantamiento, y los que en ellas se han distinguido.

12. Q Quál es su Gobierno político y económico; si tiene privilegios, y si erigió a favor de la enseñanza pública algún Seminario, Colegio, Hospital, Casa de recolección y piedad.

13. ${ }^{\circ}$ Las enfermedades que comunmente se padecen, y cómo se curan; número de muertos y nacidos, para poder hacer juicio de la salubridad del Pueblo.

14. Si tiene aguas minerales, medicinales, ó de algún beneficio para las fábricas, salinas de piedra ó agua, canteras, piedras preciosas, minas, de qué metales, árboles y hierbas extraordinarias.

15. ${ }^{\circ}$ Si hai alguna inscripción sepulcral, ú otras, en qualquier idioma se sea.

Finalmente todo quanto pueda conducir a ilustrar el Pueblo, aunque no esté prevenido en este interrogatorio.

NOTA: Procurarán los Señores formar unas especies de mapas ó planos de sus respectivos territorios, de dos ó tres leguas en contorno de su Pueblo, donde pondrán las Ciudades, Villas, Lugares, Aldeas, Granjas, Caserías, Ermitas, Ventas, Molinos, Despoblados, Ríos, Arroyos, Sierras, Montes, Bosques, Caminos, etc., que aunque no esté hecho como de mano de un profesor, nos contentamos con una sola idea o borrón del terreno, porque lo arreglaremos dándole la última mano. Nos consta que muchos son aficionados á Geografía, y cada uno de estos puede demostrar muy bien lo que hay al contorno de sus Pueblos. 


\section{EL MANUSCRITO DE LA BIBLIOTECA NACIONAL DE MADRID}

Uno de estos documentos que seguramente le fueron enviados a Tomás López es el origen del Manuscrito 12978/4 de la Biblioteca Nacional de Madrid, que lleva por título: Descripción de algunas cosas curiosas que hay en la Cuadrilla de Gamonal, fechado en 1795, dirigido a Tomás López y suscrito por el vicario de dicha Cuadrilla, afincado en Rubena, don Manuel Francisco de Paula Castilla ${ }^{7}$. La Cuadrilla de Gamonal era una de las cuatro 8 que integraban el arciprestazgo/decanato de Burgos, que junto con otros 41 arciprestazgos y seis partidos, constituían las divisiones administrativas en que se articulaba el Arzobispado de Burgos. La denominada Cuadrilla de Gamonal estaba compuesta de cuatro pueblos principales: Gamonal, Villafría, Rubena y Quintanapalla, y un conjunto de lugares menores hasta completar el número de 21 localidades $^{9}$.

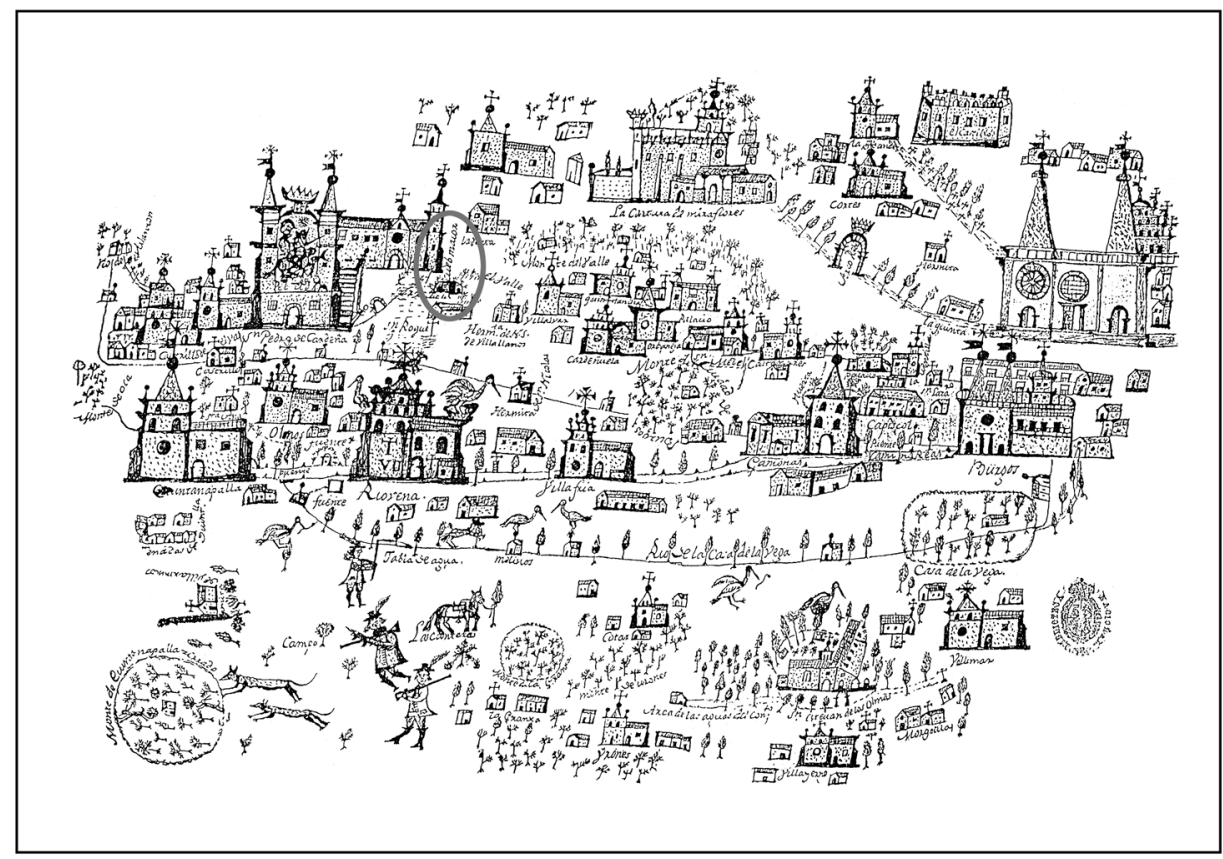

Fig. 1. Plano dibujado por don Manuel Francisco de Paula en el que aparece la Cueva Mayor.

7 Don Manuel Francisco de Paula Castilla, junto con don Josef Gil, eran curas beneficiados de Rubena. Así aparece en la documentación de la fundación de la obra pía denominada «Arca de Misericordia» de la localidad el 6 de octubre de 1770, de la cual forma parte como patrono eclesiástico. En noviembre de 1815 se hace cargo de la misma don Josef Gil, al haber fallecido recientemente don Manuel.

8 Las restantes Cuadrillas del arciprestazgo/decanato de Burgos eran Arcos de la Llana, Tardajos y Quintanadueñas.

9 Las otras localidades son: Fresno, Cortes, La Ventilla, Castañares, Cardeña la Alta, Castrillo del Val (con dos barrios e iglesias, cuyos titulares son San Juan Bautista y Santa Eugenia), San Medel, Orbaneja de Riopico, Quintanilla Riopico, Cardeñuela, Villalval, Olmos junto a Atapuerca, Villímar, Villayerno, Cótar y Hurones. 


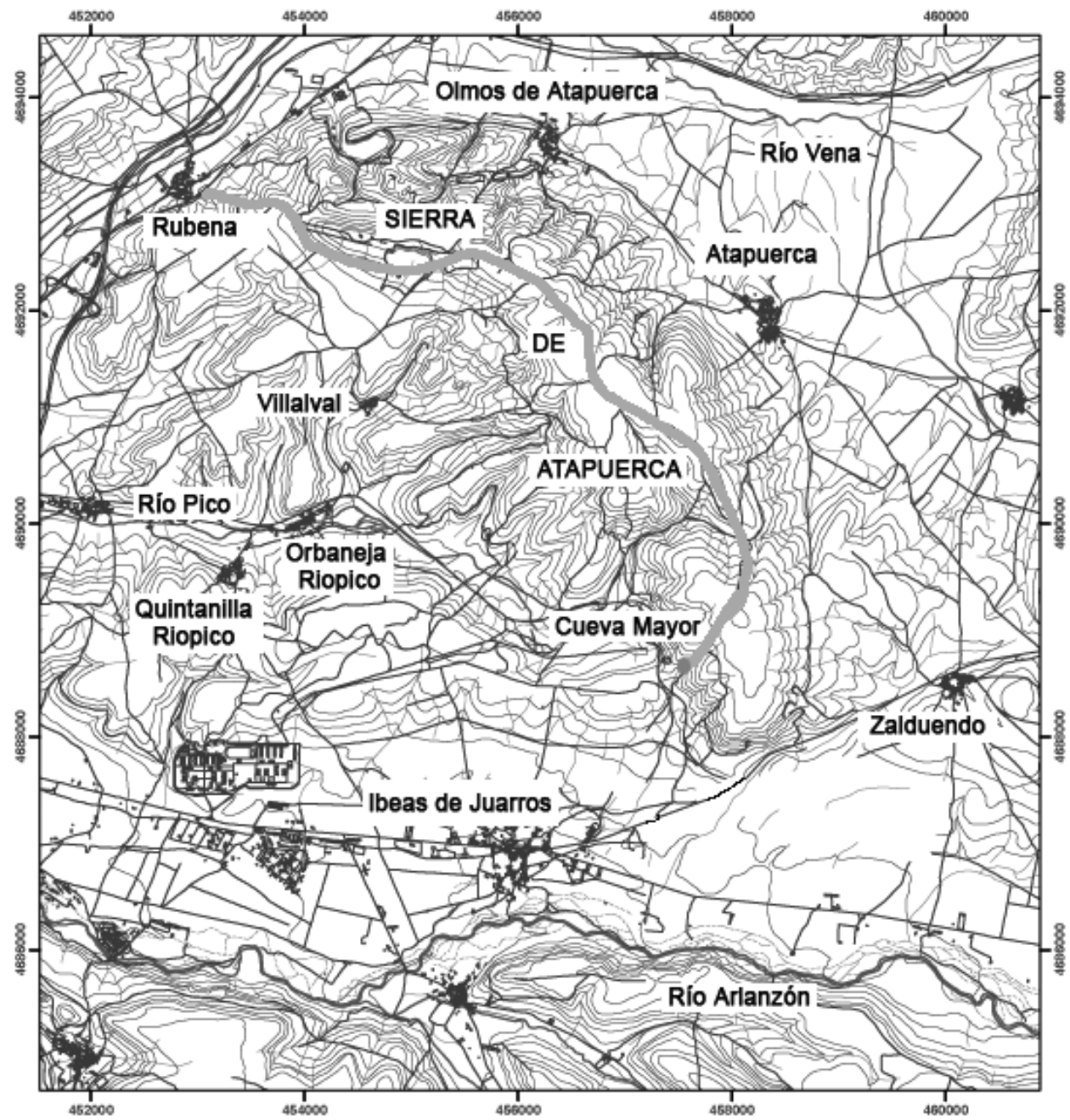

Fig. 2. Plano de situación de la Sierra de Atapuerca e itinerario recorrido desde Rubena a Cueva Mayor.

Don Manuel Francisco no contesta al cuestionario enviado siguiendo el orden establecido, es decir, punto por punto, sino de manera confusa y desordenada. Comienza refiriéndose a Gamonal, destacando su importancia histórica y el lugar destacado que ocupa en la cuadrilla, de la que es cabeza, y a continuación detalla de forma muy esquemática, sin ceñirse a los diferentes apartados, los pueblos que la componen, la distancia en leguas a la capital, los santos patronos de cada localidad y el número de clérigos que sirven las parroquias. Señala a continuación a qué jurisdicción pertenecen (realengo, señoríos civil o eclesiástico), qué ríos pasan por el término (desconoce el nombre del río Vena, al que denomina «de Casa de la 
Vega»), qué árboles, vegetación y fuentes hay en la comarca, los conventos que se encuentran diseminados por la zona, las producciones agrícolas de la comarca y otros fenómenos que atraen enormemente su atención, que él denomina «producciones de la naturaleza». Entre estas grandes «producciones de la naturaleza» destaca de manera eminente la Cueva Mayor de la Sierra de Atapuerca, a la que dedica casi la mitad del manuscrito.

\section{EL KARST DE LA SIERRA DE ATAPUERCA: CUEVA MAYOR}

La Sierra de Atapuerca se caracteriza por la existencia de un importante complejo kárstico formado en las calizas del Cretácico superior bajo condiciones freáticas $^{10}$, que alberga en sus entradas los mundialmente conocidos yacimientos pleistocenos con restos fósiles de las especies humanas predecesoras de los neandertales ${ }^{11}$, así como importantes yacimientos de la Prehistoria reciente ${ }^{12}$.

De todo el conjunto de cavidades del karst de la Sierra de Atapuerca va a destacar Cueva Mayor, por la importancia de los yacimientos que contiene y por constituir la principal red de galerías, que junto con Cueva del Silo forman un sistema de $3.700 \mathrm{~m}$ de desarrollo topografiado, representando a una de las mayores cavidades de la Cuenca del Duero. Presenta una planta en forma de aspa, con galerías que forman tres niveles nítidamente diferenciados. El superior está com-

10 Ortega Martínez, A. I., Pérez-González, A., Martín Merino, M. A., Carretero Díaz, J. M. \& ArSuAga FERRERAS J.L.: «El sistema de Cueva Mayor-Cueva del Silo: un estudio morfogenético del endokarst de la Sierra de Atapuerca (Burgos, España)», en M. SANTONJA, A. PÉReZ-GonzÁLez \& M. J. MACHADO A. (eds): Geoarqueología y Patrimonio en la Península Ibérica y el entorno mediterráneo, ADEMA, Soria, 2005, pp. 161-179.

11 Ver las obras generales: Aguirre, E., Carbonell, E. \& Bermúdez de Castro J. M. (eds): El Hombre Fósil de lbeas y el Pleistoceno de la Sierra de Atapuerca, Junta de Castilla y León, Consejería de Cultura y Bienestar Social, 1978, 439 pp.; ARsuaga J. L., BermúdeZ de CASTRo J. M. \& CARBonelL, E. (eds): Journal of Human Evolution, 33 (2/3), 1997; CarbonelL, E., BermúdeZ de CASTRo J. M. \& ArsuagA J. L. (eds): Journal of Human Evolution, 37 (3/4), 1999; CARBonell, E., Rosas, A. \& DíEz, C. (eds): «Atapuerca: Ocupaciones humanas y paleoecología del yacimiento de Galería», Memorias 7, 1999; CARBONELL, E., ARsuaga J. L. \& Bermúdez de CASTRO J. M. (eds): L'anthropologie, 105 (1/2), 2001.

Publicaciones divulgativas: Arsuaga, J. L., Bermúdez de Castro, J. M., Carbonell, E. \& Fernández, J. J. (eds) (e.p.): Guía de los yacimientos de la Sierra de Atapuerca, Junta de Castilla y León; BERMúDEZ de Castro, J. M., Arsuaga, J. L., Carbonell, C. \& Rodríguez, J. (eds.): Catálogo de la Exposición «Atapuerca, nuestros antecessores», Junta de Castilla y León, 1999. CerverA, J., ARsuAGA, J. L., BeRmúdez de CAstro, J. M. \& Carbonell, E.: Atapuerca. Un millón de años de historia, Ed. Complutense, Madrid, 1998.

12 Ver obras: ApELLÁNIZ, J. M. \& URIBARRI, J. L.: «Estudios sobre Atapuerca (Burgos) I. El Santuario de la Galería del Sílex», Cuadernos de Arqueología de Deusto, 5, 1976; ApellánIZ, J. M. \& Domingo, M.: «Estudios sobre Atapuerca (Burgos) II. Los materiales de superficie del Santuario de la Galería del Sílex», Cuadernos de Arqueología de Deusto, 10, 1987; Ruiz, B., Ortega, A. I., Dorado, M., Valdeolmillos, A., Gil, M. J., Arsuaga, J. L., Carretero, J. M., Martínez, I. \& Pérez-González, A.: «Vegetational history during Bronze and Iron ages in Portalón Cave (Sierra de Atapuerca, Burgos, Spain)», en Ruiz Zapata et al. (eds): Quaternary climatic changes and environemental crises in the mediterranean region, 99-106, 2002; JUEZ APARICIO, L.: Estudio tipológico y contextualización de los materiales cerámicos recuperados en el yacimiento del Portalón de Cueva Mayor (Sierra de Atapuerca, Burgos), Trabajo de Investigación, Universidad de Burgos, inédito, 2005. 


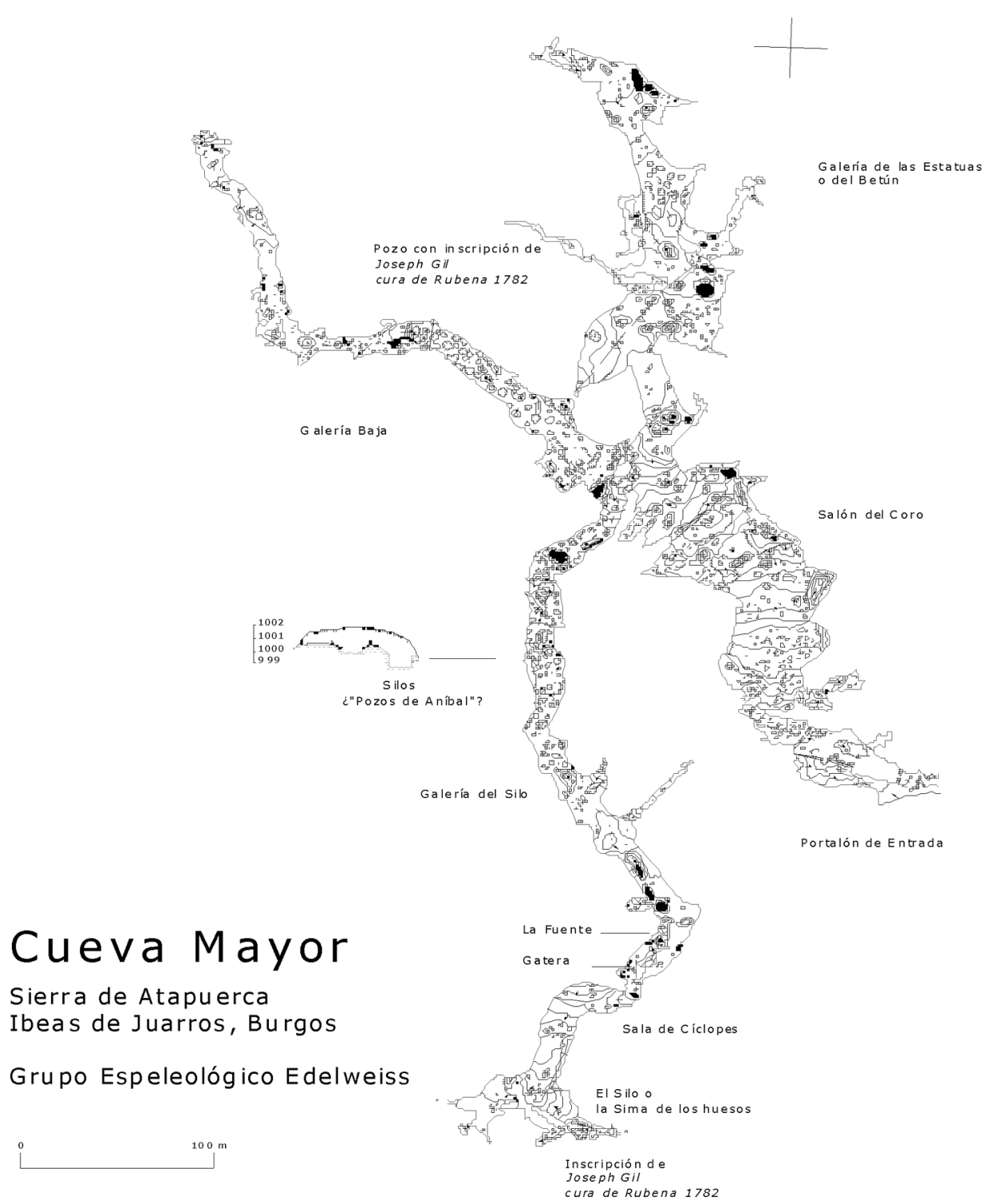

Fig. 3. Plano de las galerías conocidas de Cueva Mayor en el siglo XVIII (Topografía: Grupo Espeleológico Edelweiss, de la Excma. Diputación Provincial de Burgos).

puesto por la Galería del Sílex (descubierta en 1972), el Salón del Coro y la Galería de las Estatuas o del Betún, el intermedio por la Galería Baja y la Galería del Silo, y el nivel inferior por la Sima de los Huesos y los conductos de Cueva del Silo.

El conocimiento científico de Cueva Mayor se debe a los ingenieros de minas P. Sampayo y M. Zuaznávar, quienes publican el primer estudio y exacta topo- 


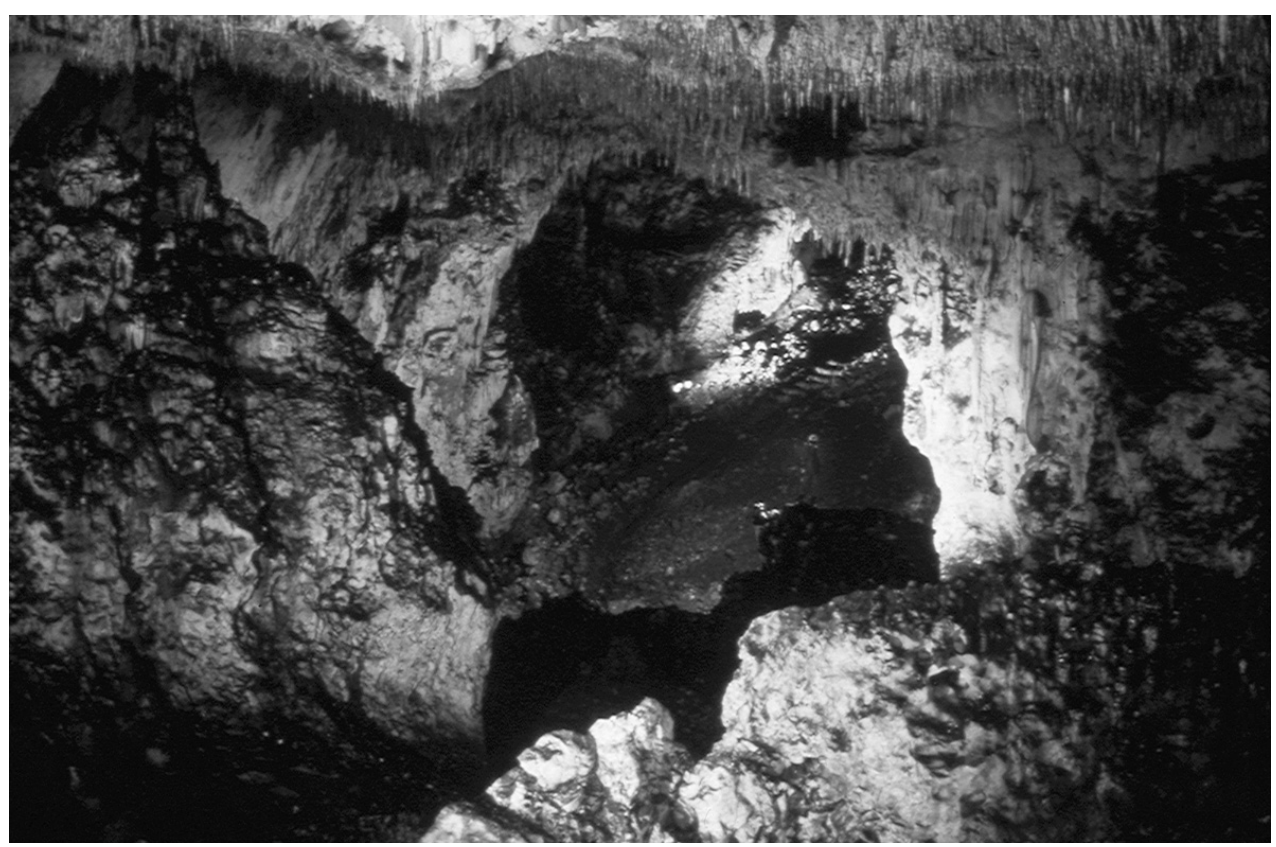

Fig. 4. Vista del Salón del Coro (Foto: F. Lázaro, Archivo GEE).

grafía de la cavidad en $1868^{13}$, a los trabajos de investigación, catalogación y exploración espeleológica realizados por el Grupo Edelweiss, desde la década de los 50 , por constituir el estudio completo del karst ${ }^{14}$, y a las diferentes investigaciones arqueo-paleontológicas desarrolladas a partir de la década de los $70^{15}$.

Pero el conocimiento popular de Cueva Mayor puede deberse a que constituye, a partir de la Edad Media, un hito geográfico entre las localidades del entorno, datando en el siglo $X$ la primera referencia documental ${ }^{16}$ y en el siglo XVI la primera noticia publicada sobre una visita de la corte de Carlos $\mathrm{V}$ a su interior, por parte de don Francés de Zúñiga bufón del Emperador ${ }^{17}$, así como la primera descripción de la cueva según el relato que se hace en una carta dirigida a Felipe II el 23 de abril de $1576{ }^{18}$. De estas visitas se conservan numerosísimas inscripciones y grafittis en paredes y concreciones de su interior, que dan constancia del paso de gentes des-

13 Sampayo, P. \& Zuaznávar, M.: Descripción con planos de la cueva llamada de Atapuerca, T. Arnáiz. Burgos, 1868.

${ }_{14}$ Martin Merino, M. A., Domingo, S. \& Antón, T.: «Estudio de las cavidades de la Zona BU-IV.A (Sierra de Atapuerca)», Kaite, Estudios de Espeleología Burgalesa, 2, 1981, pp. 41-76.

15 Ver bibliografía notas 11 y 12.

16 Serrano, L.: Becerro Gótico de Cardeña, Valladolid, 1910, pp. 20-22.

17 Ortega Martínez, A. I. \& Martin Merino, M. A.: «Visita a la Cueva de Atapuerca en 1527, según la 'Crónica burlesca del Emperador Carlos V' de don Francés de Zúñiga», Cubía, 8, 2005, pp. 26-31.

18 LóPEZ TORRIJOS, R.: «Visitas a las cuevas de Atapuerca y Santander en el siglo XVI», Boletín Museo e Instituto Camón Aznar, XCVII, 2006, pp. 194-195. 
de posiblemente el siglo XIII ${ }^{19}$ y claramente desde el siglo XVI, destacando por su número y ubicación las de los siglos XVIII y XIX, debido al interés que centra el conocimiento de la Naturaleza ${ }^{20}$.

\section{LA CUEVA MAYOR DE LA SIERRA DE ATAPUERCA SEGÚN LA DESCRIPCIÓN DE DON MANUEL FRANCISCO DE PAULA CASTILLA}

Para don Manuel Francisco de Paula Castilla la Cueva Mayor «es una de las producciones en la esfera de la naturaleza que deben admirarse» de la que no se tenían noticias publicadas, y por lo tanto tiene la esperanza de que don Tomás López, geógrafo real, a quien van destinadas las respuestas, acogerá benévolo tal información y la incluirá en sus mapas. Lo primero que hace en su escrito es situar la cueva:

En los confines, y consunos de los Lugares de Atapuerca, Ybeas, y Cardeñuela, en sus términos intitulados Las Torcas y Valdecuende,... está situada esta memorable Cueba, producción bien rara de la naturaleza, sin haver intervenido en su formacion la industria humana. La entrada principal, que es por un Callejon de crecidos peñascos, mira casi al meridiano; y por aquí la primera vista que se descubre, es la de un grabe Portico construido de iguales peñascos ${ }^{21}$.

Cuenta a continuación don Manuel Francisco de Paula que, en los años 17821783 y 1792-1793, había entrado mucha gente en particular labradora en esta cueva, y que, en fecha sin determinar anterior al verano-otoño de 1795, el cabildo y justicia de Rubena, acompañados de gente del pueblo, bien provistos de «luzes, yesca, piedras y eslabones», dirigidos todos por el clérigo don Josef Gil de Matha, su compañero beneficiado de Rubena, «de poco cuerpo, pero de mucho espíritu», volvieron a repetir la operación, dándole cuenta a don Manuel de las «aventuras y sucesos» vividos, de tal forma que nuestro clérigo se animó, no sin temor, a penetrar en «esta espantosa Cueba».

Así que bajamos aquella escalera tan larga y penosa de cantos, cantamos la Magnificat con otros salmos, alabando al Criador en sus obras ${ }^{22}$.

El grupo de exploradores que acompaña a don Manuel, tras descender el Salón del Coro, escoge el camino de la derecha por donde avanzan un largo trecho, adentrándose en la Galería de las Estatuas y Galería Baja; luego vuelven sobre sus pasos, al comprobar que la galería concluye en un lugar donde ya no se

19 Sampayo, P. \& Zuaznávar, M. (1868): Descripción con planos.... pp. 12-13.

20 Ortega Martínez, A. I.: «Historia de las intervenciones arqueológicas en Atapuerca», en BERmúdeZ de Castro J. M., Arsuaga J. L., Carbonell, E. \& Rodríguez, J. (eds): Atapuerca nuestros antecesores, Junta de Castilla y León, 1999, pp. 36-52.

21 Biblioteca Nacional. Manuscritos (en adelante BN. Mss.) 12978/4, pp. 13-14.

22 BN. Mss. 12978/4. p. 16. 


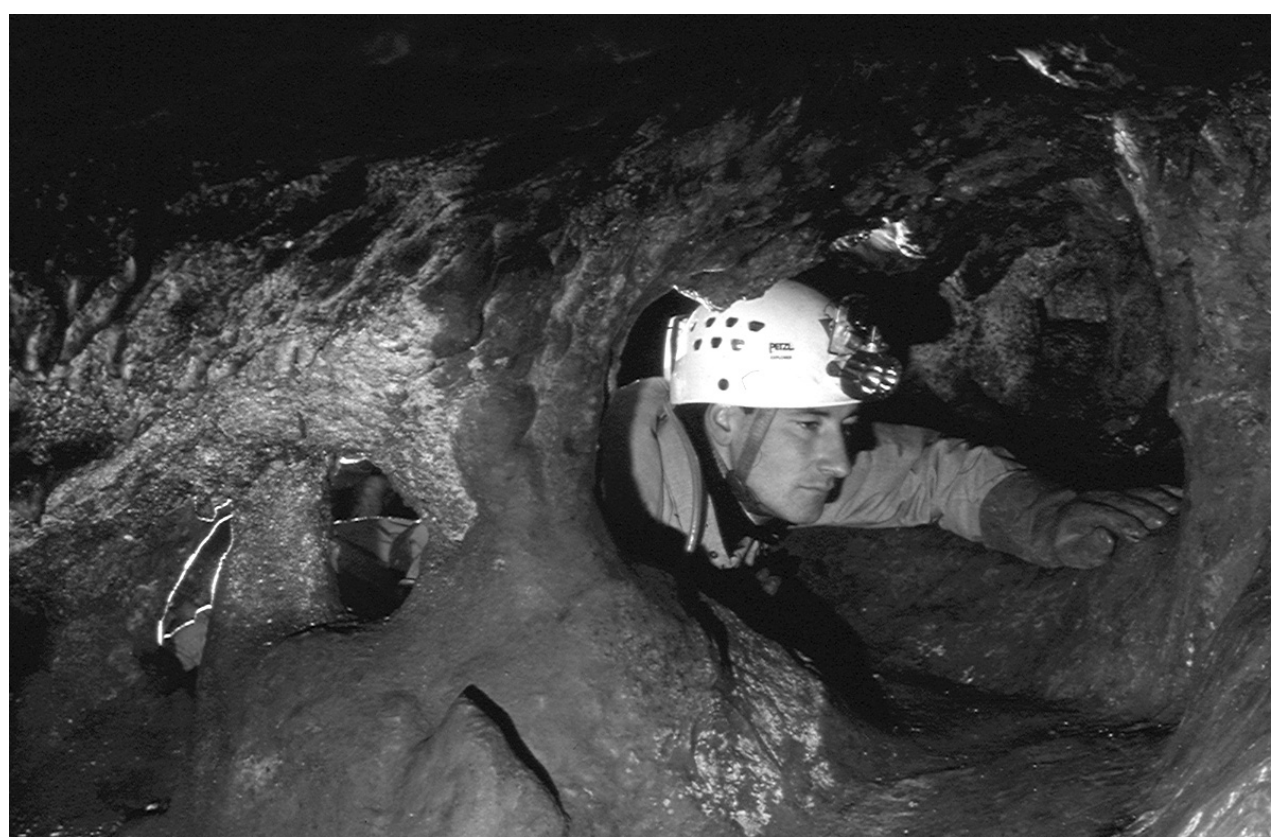

Fig. 5. Vista de la Galería del Silo (gatera) (Foto: M.A. Martín Merino, Archivo GEE).

puede seguir más adelante y avanzan por el conducto izquierdo, por la denominada Galería del Silo. En su recorrido, a don Manuel le llama la atención el enorme contraste de proporciones que se dan en la cueva.

Por partes, la bobeda de esta Cueba es tan elevada, que compite, si no sobrepuja a la de la nave de la Yglesia mas alta, por otras partes es tan baja, que no llega a la de una pequeña hermita, y por otras es preciso pasar arrastrando como las Culebras por los abujeros de sus estrechos peñascos ${ }^{23}$.

Llama la atención de nuestro vicario la presencia de formaciones estalagmíticas dignas de admiración, entre las que destaca la localizada antes de la gatera que da acceso a la Sala de los Cíclopes, una colada con pequeños gours, columnas y estalactitas, de las que destila un hilo de agua cristalina que se recoge en lo que él denomina «fuente de echura tan peregrina»:

De esta agua asi destilada, y mezclada con varias particulas que va lamiendo la piedra, se conglutina aquella masa con que la naturaleza, tomandolo de espacio, haze aqui prodigios, y portentos, y así la mayor parte del cielo de esta Cueba esta cubierto de una especie de caramelos grandes, y pequeños, semejantes a aquellos, que con el rigor del yelo vemos pendientes en los texados ${ }^{24}$.

23 BN. Mss. 12978/4, p. 16.

24 BN. Mss. 12978/4, p. 17. 
Ante tal espectáculo quedaron tan anonadados que se vieron en la necesidad de reponer fuerzas con un frugal almuerzo, regado con generoso vino

... que despues de alegrarnos el corazon, nos comunico tanto valor, y aliento, que con el mismo plazer andabamos por esta Cueba, que nos pintaban tan espantosa, que por una sala cubierta de alfombras, vistosa y clara ${ }^{25}$.

Don Manuel, ya más confiado y alegre y comprobadas las propiedades terapéuticas del vino, viene a rememorar las leyendas más fantásticas, que considera «enrredos, embustes y patrañas», que sobre la cueva existen y circulan entre las gentes de la comarca. La primera que cita, habla de la existencia en la cueva de largos ríos verdes, profundos e intransitables; otra que había «grandes quadras de pavorosos toros"; otra cuenta que hay «salas espaciosas y adornadas camaras, y havitaciones de Damas mui peregrinas, y que en sus Antesalas estaban los Galanes, y escuderos armados con las bayonetas caladas, y alfanjes desnudos ${ }^{26}$.

La exploración prosiguió pero debido a la dificultad del recorrido, ya que deben superar la gatera que da acceso a la Sala de los Cíclopes y al Silo o la Sima de los Huesos, aconsejan a don Manuel, que confiesa en su escrito «ser de edad algo avanzada», que no siga adelante, ya que para él «lo restante del camino por sus altos y bajos tan agrios y resbaladizos era intransitable».

El vicario, no obstante, detalla cómo su animoso compañero, don Josef Gil, mandó explorar todos los pozos y silos de Cueva Mayor, y así narra en su escrito cómo bajaron al Silo, atados «con sogas por debajo de los brazos, y llevando en las manos cada uno su luz», los dos muchachos de trece a catorce años y su compañero beneficiado, hallando un gran número de huesos, entre los que sacan un colmillo «de medio jeme ${ }^{27}$ de largo y a proporción de grueso».

La existencia de tantos huesos en este Silo plantea interrogantes a nuestro clérigo que no acierta a comprender, justificando en un primer momento la presencia del colmillo que tiene en su poder porque «fuese de alguna espantosa fiera, criada en estas sierras» o en otras próximas, ya que según nos cuenta no hacía mucho que se había divulgado la siguiente noticia por la comarca

que una sierpe muy horrible se desprendió de la Sierra de Pineda, a mamar las bacas de Villafranca: y que se apacentaban en los montes de oca, en un termino llamado La Pedraja: y que el Pastor del Boticario de esa Villa, haviendola visto, le infundio tanto miedo, que le hizieron no se quantas sangrias, para que volviese del susto 28 .

También indica que este colmillo pudo pertenecer a «otro animal de igual especie, jabalí o lobo» que habitan en estos montes, y que se hubiese caído a la

25 BN. Mss. 12978/4, p. 18.

26 BN. Mss. 12978/4, p. 18.

27 Distancia que media entre el dedo pulgar y el dedo índice, separando el uno del otro todo lo posible.

28 BN. Mss. 12978/4, p. 20. 


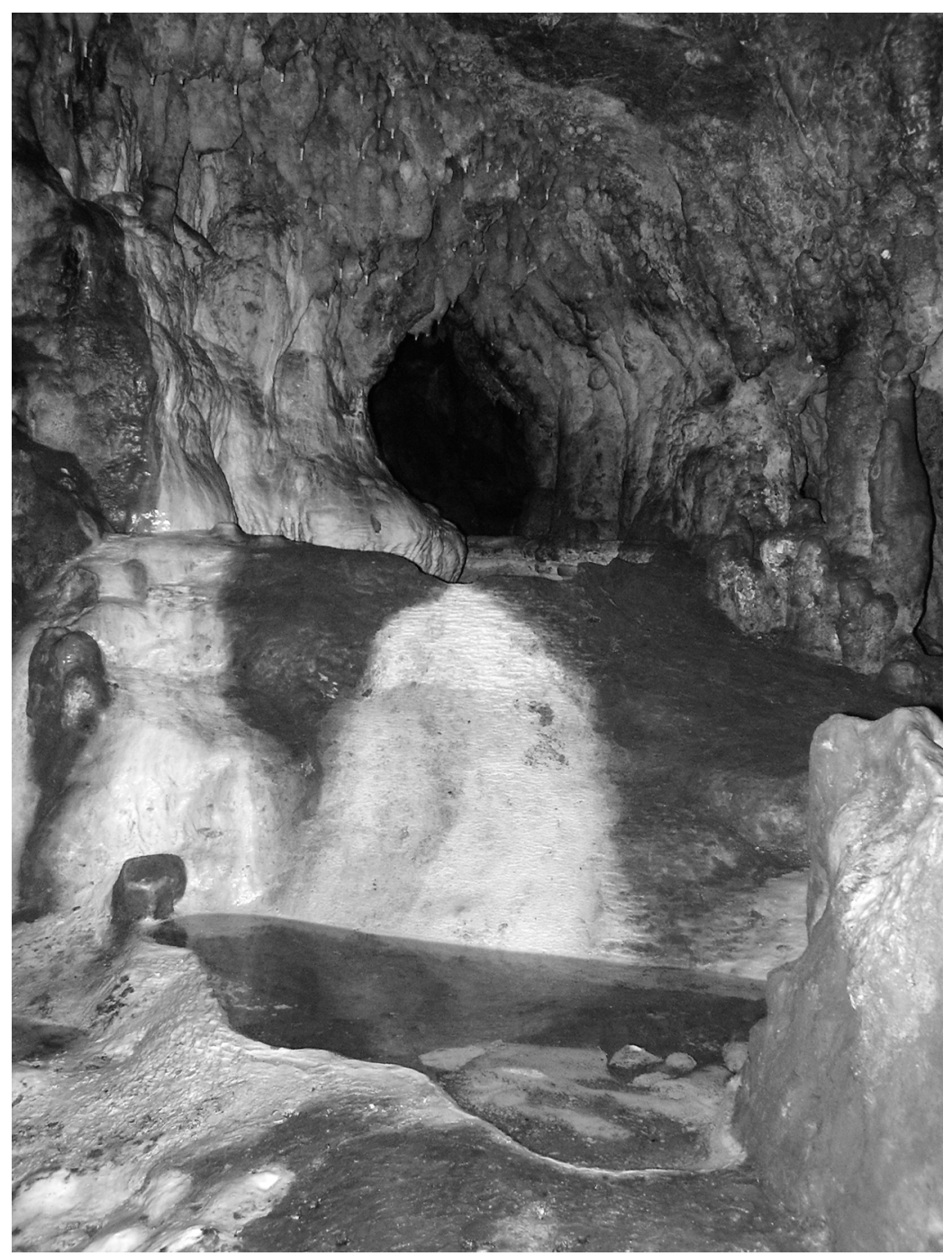

Fig. 6. Vista de la Galería del Silo (fuente) (Foto: M.A. Martín Merino, Archivo GEE).

sima al ser perseguido por los cazadores. Por las dimensiones del colmillo deduce que debía corresponder a un animal muy corpulento y, según él, dadas las pequeñas dimensiones que presentan algunos tramos de la Galería del Silo, los animales debieron llegar al pozo «echos quartos y menudos pedazos».

Siguiendo el discurso que nos presenta, intenta argumentar la presencia de los huesos sobre la base de las leyendas que más arriba ha descrito, aunque no acierte a creérselas. Une la leyenda de los toros con la de las damas y argumenta que 


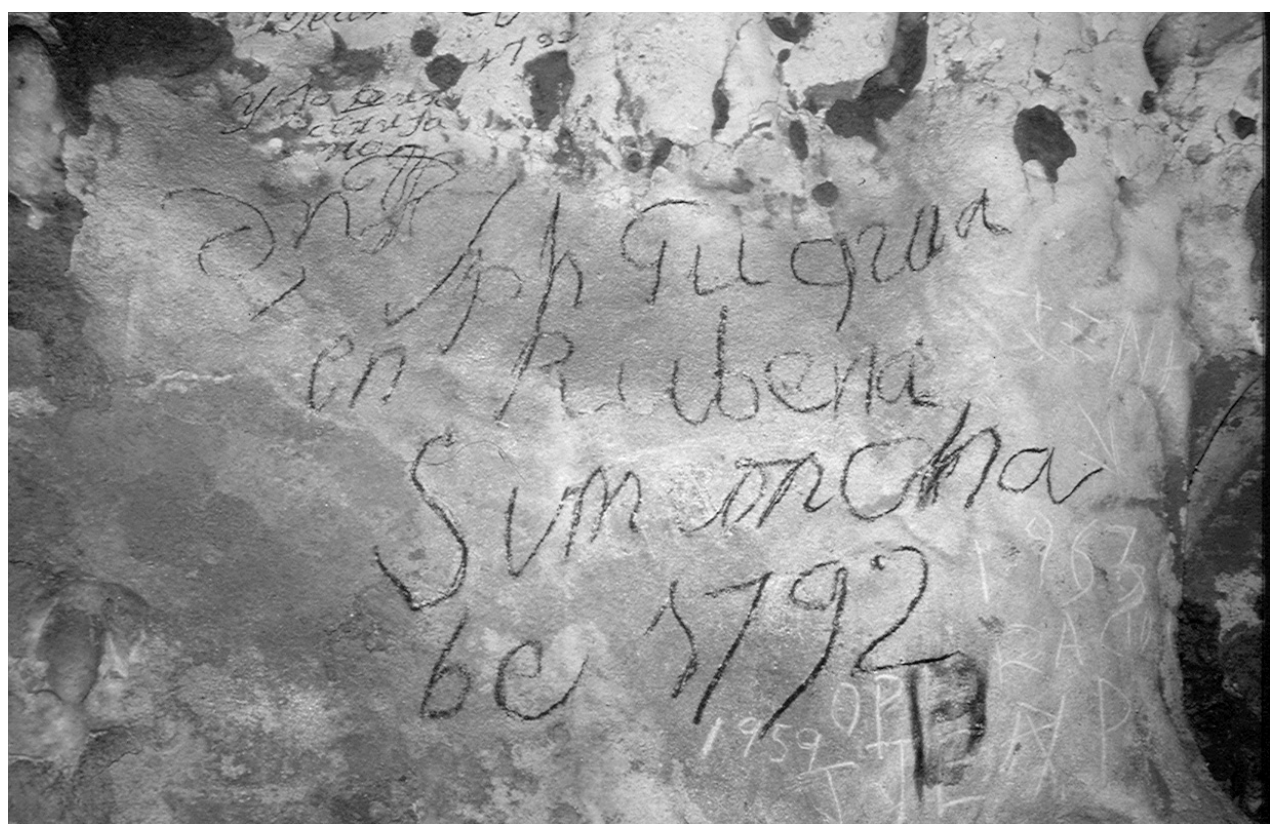

Fig. 7. Graffiti de Joseph Gil 1792 (Foto: M.A. Martín Merino, Archivo GEE).

este poço lleno de guesos tan grandes, son de toros muertos a estocadas, artos de correrse, y de aquellos Galanes, Escuderos y madamas, que enamorados asta las cachas, perdieron los ultimos alientos, fatigados de amarse ${ }^{29}$.

Otra explicación, a su entender más verosímil, viene de la mano de una nueva leyenda que dice que «esta Cueba la havitaron por largo tiempo los moros» y que las mujeres lavaban la ropa de sus infantes en una fuente que hay a «un tiro de bala» llamada en el documento precisamente de «La Mora» ${ }^{30}$, denominación que los labradores testifican haber oído a sus ascendientes. Bien pudiera ser -afirma- que este pozo sirviera de "osario de los moros, moras y moritos".

Aunque también cree que se podría encontrar una demostración a la acumulación de restos óseos en el fondo de la sima en relación con la actividad vinculada a los «Pozos de Aníbal». Para el autor, cuando los cartagineses conquistaron parte de la Península, sacaron mucho oro y plata de las entrañas de nuestras sierras, cuyas minas se denominaron Pozos de Aníbal, y aunque don Manuel preguntó al efecto a «historiadores aplicados y curiosos», ninguno supo darle razón alguna. La presencia de los numerosos silos vistos en su visita a las galerías de Cueva Mayor, le convenció de que estaba ante los referidos pozos, para lo cual

29 BN. Mss. 12978/4, p. 20.

30 En la actualidad se denomina Fuente del Moro, situada en la ladera meridional del Valle de Valhondo, en término de Espoleares. Con la concentración parcelaria se han destruido los sillares que la encauzaban. 


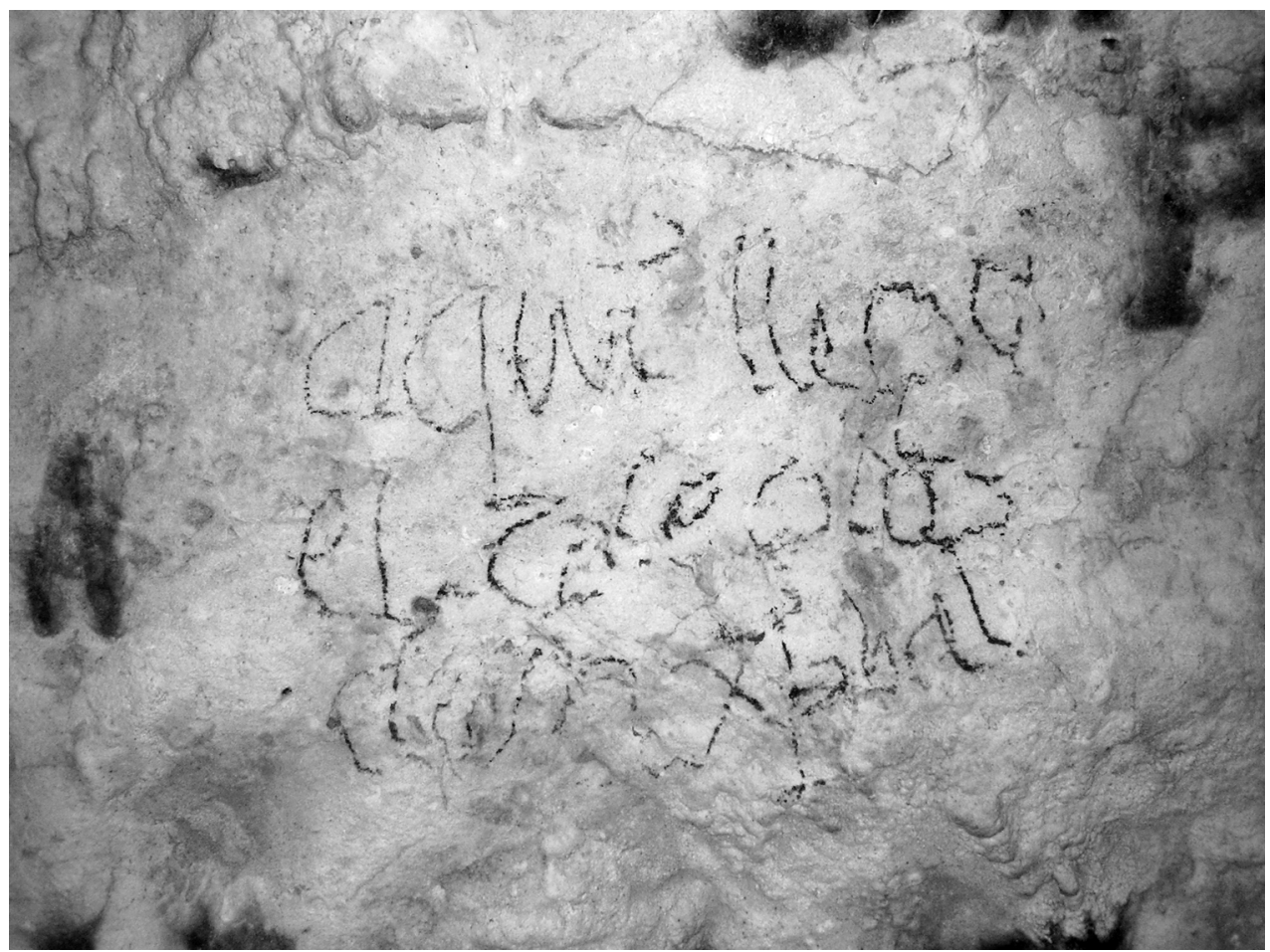

Fig. 8. Graffiti de la visita de San Cristóbal de Ibeas (Foto: M.A. Martín Merino, Archivo GEE).

trae a colación una quinta leyenda según la cual se creía que había minas de oro y plata, argumentando «que el sitio es muy aparente para la producción de estos metales», por lo que los restos del fondo de la sima podrían ser de aquellos ambiciosos mineros africanos que muriesen.

Una última posible interpretación que apunta para comprender la gran acumulación de huesos, tanto de humanos como de animales, es la que los relaciona con la batalla de Atapuerca, ocurrida en 1054, en el Campo de la Matanza al Este de la Sierra, entre Fernando I de Castilla y su hermano García de Navarra, por la posesión de La Bureba y La Rioja. El depósito de huesos de la sima sería para nuestro personaje el último destino de los muertos de la batalla, indicando que

pudo acontezer que rompiesen por su bobeda y abrir por aqui un vocaron, que caiese recto, y perpendicular a este pozo, y arrojar por el los hombres, y caballos, que havian fenezido en el Campo y ser de estos la multitud, de tantos disformes y desiguales guesos ${ }^{31}$.

Explorada la Sima de los Huesos ya no pudieron pasar más adelante y dibujaron en la pared esta inscripción: non plus ultra, dando por finalizada la explora-

${ }^{31}$ BN. Mss. 12978/4, p. 22. 

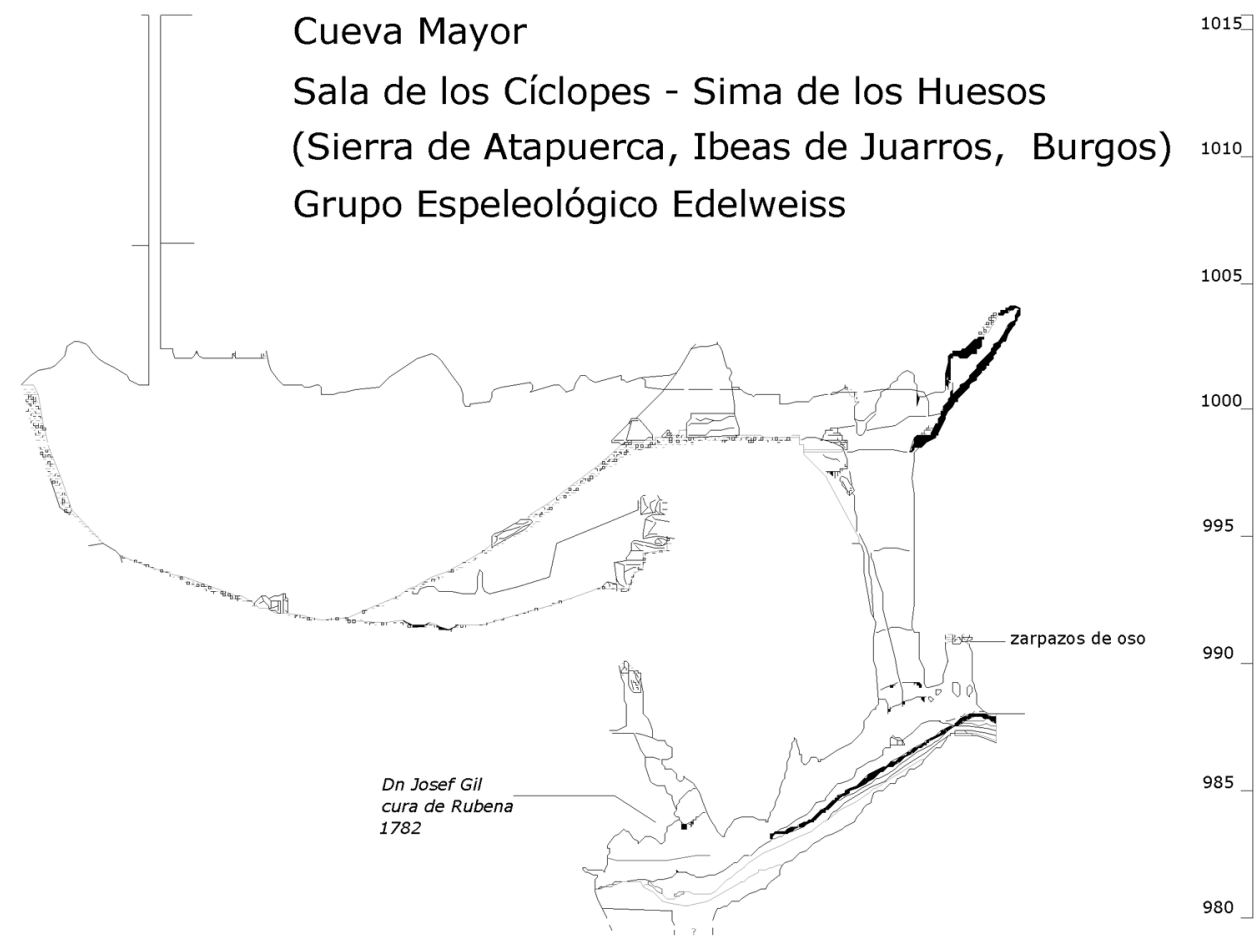

Fig. 9. Sección de la Sima de los Huesos (Topografía: Grupo Espeleológico Edelweiss).

ción de Cueva Mayor. El documento está fechado en Rubena, el 1 de noviembre de 1795.

Todavía 60 años más tarde de que don Manuel Francisco descendiera a la cueva, Pascual Madoz, continuador del trabajo de Tomas López, tan sólo hace una escueta referencia llena de interrogantes a la cueva de Atapuerca en su Diccionario:

no se puede penetrar en ella sin luz artificial y cuerda, ni á pesar de las varias tentativas nunca se ha podido hallar el fin por sus muchas tortuosidades; se notan algunas escavaciones que se ignora para qué fueron hechas, y a los 3/4 de legua de profundidad se halla una pequeña, pero muy hermosa fuente de buena calidad y cristalina; su techo aparece cubierto de varias figuras formadas por la petrificación de las aguas que por él se infiltran ${ }^{32}$.

En esta descripción podemos observan la base de información de don Manuel Francisco, al resumir los aspectos más generales y comunes de la cavidad, que para Madoz dice «se cree ser natural», como son su longitud y dificultad, la pre-

32 Madoz, P.: Diccionario Geográfico-Estadístico-Histórico de España. Burgos, Valladolid, Ámbito, 1845-1850 (edic. facsímil de 1984), p. 64. 


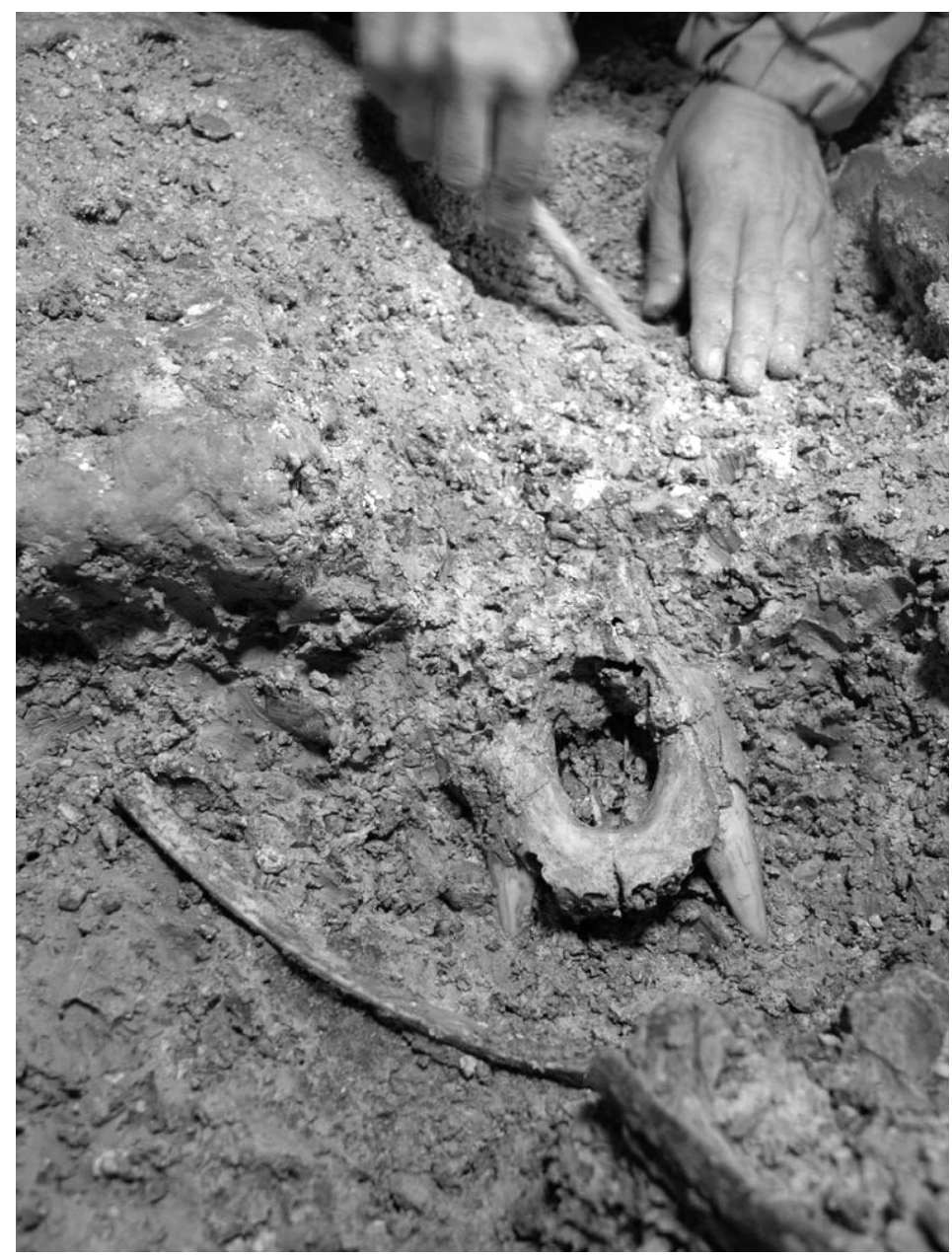

Fig. 10. Toma de la Sima de los Huesos (Foto: Javier Trueba).

sencia de los silos excavados, de los que no se conoce su funcionalidad, así como la existencia de la Fuente y de las estalactitas. Por algunos datos de longitud y localización podríamos intuir que Madoz debió manejar algún posible croquis o plano de la cavidad. En esta descripción debemos destacar la total ausencia de datos referidos a la acumulación de huesos en el fondo del Silo o Sima de los Huesos que tanto preocupaba a nuestro investigador, muy posiblemente debido a la incomprensible e inverosímil presencia de un yacimiento tan excepcional en la primera mitad del siglo XIX, momento en el que no había despegado la ciencia de la Prehistoria.

Habrá que esperar a las actuaciones de Felipe de Ariño, en 1863, y de Pedro Sampayo y Mariano Zuaznávar, en 1868, para que se abra un camino seguro y, ya 
en el siglo XX, se comiencen a recoger los frutos copiosos de los múltiples continuadores que han prolongado hasta el presente los esfuerzos de estos primigenios y asombrados naturalistas e investigadores.

\section{CONCLUSIÓN}

En un tiempo, en el que la cultura del clero va desde el refinamiento de una minoría que frecuentaba las universidades hasta la penuria de quienes apenas sabían «medianamente leer y poco construir e cantar bien» ${ }^{33}$, cuando muchos clérigos no estaban en condiciones de predicar y ni siquiera de impartir una elemental catequesis al pueblo, el vicario de Rubena aparece como un personaje singular dotado de una notable cultura, de capacidad de observación y de una actitud crítica ante lo que está viendo.

A través de su Descripción se pueden destacar muchos aciertos:

$\left.1 .{ }^{\circ}\right)$ La relevancia del documento, ya que hasta el momento presente es el primer texto hallado que describa con detalle la Cueva Mayor; $2^{\circ}$ ) la minuciosidad con que el autor detalla el recorrido, desde su pueblo de Rubena a la Cueva, a través de los términos de San Roque y la Serrezuela; la orientación y descripción de su entrada y la especificación de lo observado en su interior, donde mezcla sus reflexiones con las fabulaciones al uso, en las que como buen ilustrado no acaba de creer, pero tampoco descarta porque está convencido de que «la sierra nominada, aunque a primera vista parece estéril e infecunda, que sólo produce encinas, espinos y carrascos, si bien se registra y desentraña está llena de riquezas y tesoros»34; 3.॰) la precisión de sus conocimientos históricos, como por ejemplo, cuando detalla la relación que con Gamonal tenían las infantas doña Urraca y Doña Elvira, hijas del rey Fernando I y hermanas de Alfonso VI; la fundación de la Cofradía de los Caballeros de Gamonal; que fue sede del obispado antes de su traslado a San Llorente de Burgos; la actuación de San Lesmes en el encauzamiento de las aguas de los ríos Pico y Vena en su confluencia en la ciudad de Burgos y las capitulaciones de boda del rey Carlos II en Quintanapalla. Conoce el monasterio de San Pedro de Cardeña y que allí estaba enterrado el Cid y doña Jimena; la fundación de la Cartuja en los palacios de Enrique III, el incendio que lo redujo a ruinas y el empeño de la reina Isabel para erigir un enterramiento digno para su padre, el rey Juan II, y está informado de la actividad de Felipe de Vigarny, el Borgoñón, en la catedral de Burgos; y $4 .^{\circ}$ ) tiene noticia de la visita efectuada seguramente tres años antes por escolares y novicios del monasterio de San Cristóbal de lbeas y, como aportaciones más importantes, realiza una interesante descripción arqueológica de la bajada a la Sima de los Huesos, reseña de las inscripciones halladas, detallando si estaban realizadas a tinta, lápiz, carbón o humo,

33 VV. AA.: Historia de Burgos, III, Edad Moderna (1), Caja de Ahorros Municipal, 1991, p. 370.

34 BN. Mss. 12978/4, p. 15. 
y refleja en su escrito las formaciones geológicas que encuentra (caramelos petrificados o estalactitas, fuentes o gours, etc.), enterramientos y silos que observa en su recorrido.

No obstante, también deben ser subrayadas algunas imprecisiones o inexactitudes, como la desorientación de algunas de las referencias del plano dibujado por el autor (principalmente en relación con el valle del Pico); el desconocimiento del nombre del río Vena, la no indicación del río Pico o la atribución de los jaspes del trascoro de la Catedral de Burgos a las canteras de Atapuerca.

A pesar de ello, sin embargo, Manuel Francisco de Paula Castilla es consciente de la importancia de su aportación al interés científico, lamenta no haberla podido hacer más exhaustiva por falta de medios económicos y, sobre todo, espera un reconocimiento expreso, tanto para él como para los que le han ayudado, en el futuro Diccionario Histórico-Geográfico que se va a llevar a cabo, en el cual no se llegó a valorar ni reconocer en su justa medida la información proporcionada ${ }^{35}$.

35 Este trabajo no hubiera sido posible sin las facilidades prestadas por los miembros del Grupo Espeleológico Edelweiss, de la Excma. Diputación de Burgos, por la planimetría y fotografías proporcionadas, a quien agradecemos su colaboración y en especial a Miguel Ángel Martín, por su disposición, quien además ha leído atentamente el manuscrito. 